\title{
Seleção por Consequências: Desdobramentos para a Noção de Ciência de B. F. Skinner
}

\author{
Nilza Micheletto \\ Pontifícia Universidade Católica de São Paulo
}

\begin{abstract}
RESUMO
O sistema explicativo de B. F. Skinner transforma-se ao longo de sua construção. Nos primeiros anos, Skinner propõe que explicação é descrição de relações funcionais entre eventos diretamente observáveis do organismo e ambiente. A noção de causalidade de seleção por consequências, relacionada à proposição do comportamento operante, terá desdobramentos para pressupostos relativos ao objeto de estudo, à relação entre o sujeito e objeto do conhecimento, à concepção de ciência e aos procedimentos adotados para produção de conhecimento científico efetivo. Nesse artigo, busca-se identificar alguns desdobramentos do modelo causal de seleção por consequências para as propostas de Skinner para a ciência.
\end{abstract}

Palavras-chave: análise do comportamento; noção de causalidade; teoria do conhecimento.

\begin{abstract}
Selection by consequences: deployments for the notion of science of B. F. Skinner

B. F. Sknnner's explanatory system is transformed throughout its construction. In the early years, Skinner proposes that explanation is description functional relationships between directly observable events of the organism with environment. The notion of selection by consequences, related proposition of operant behavior, will have unfolding for assumptions related to the subject matter, the relationship between subject and object of knowledge, the concept of science and the procedures used for the production of effective scientific knowledge. In this article we aim to identify some unfolding of the causal model of selection by consequences for the Skinner's proposal for science.
\end{abstract}

Keywords: behavior analysis; causality; theory of knowledge.

A visão determinista do comportamento humano de Skinner gerou rejeição a suas propostas por críticos defensores de um homem livre e criativo, capaz de escolhas e de agir contra formas de controle (Bjork, 1996; Skinner, 1973, 1974). A suposição do comportamento dos organismos como determinado pode ser identificada desde seus primeiros textos da década de 1930 até o último, publicado em 1990. Entretanto, a noção de determinação, entre outras proposições, se altera ao longo da construção do seu sistema teórico. Vários fatores foram indicados pelo próprio Skinner como estando relacionados à crítica de suas propostas. Um fator marcante é o que parece ser um desconhecimento desse sistema. Skinner (1973), em sua publicação "Answers for my critics", afirma: “[...] a maioria dos meus críticos tem mostrado surpreendente má compreensão da ciência [do comportamento]" (p. 256-257). A construção do modelo causal de seleção por consequências acompanha e traz alterações nas proposições iniciais de Skinner que podem ter dificultado o conhecimento de seu sistema elaborado com base no conceito de operante.

Em 1931, Skinner apresenta um programa para análise do comportamento de organismos intactos, que se desenvolve tendo como base o conceito de reflexo. Ao fazê-lo, Skinner tem que enfrentar as questões do determinismo e da espontaneidade, da intencionalidade e da finalidade, que são usadas por teorias do momento para explicar os comportamentos dos organismos vivos. A proposta do reflexo como unidade de análise do comportamento não favoreceu a identificação da distinção que Skinner estabeleceu, a partir de uma análise histórica do conceito, entre suas noções de reflexo e de explicação e as noções alternativas então vigentes.

A partir de uma análise histórica deste conceito de reflexo, buscando se afastar de "interpretações supérfluas" [com base em propriedades intrínsecas, tais como força condutora, irritabilidade] do conhecimento até então formulado, Skinner propõe a descrição do comportamento em termos de reflexo, entendido como uma correlação observada entre estímulo e resposta. Skin- 
ner, nesse momento, explicita sua noção de determinação e de explicação, ao indicar que descrever é igual a explicar:

\section{[...] estamos interessados no que o organismo $\mathrm{faz}$.}

Mas a descrição do comportamento, se é para ser tanto científica e satisfatória, deve ir além. Como uma disciplina científica, ela deve descrever o evento não só em si mesmo mas em sua relação com outros eventos; e, em termos de satisfação, ela deve explicar. Essas são atividades idênticas. [...] Podemos adotar agora esta visão mais humilde de explicação e de causação, que parece ter sido primeiramente sugerida por Mach e que na atualidade é característica comum do pensamento científico, em que, em uma palavra, explicação é reduzida à descrição e a noção de função substitui a de causa. A descrição completa de um evento é realizada de forma a incluir a descrição de sua relação funcional com eventos antecedentes. (Skinner, 1931/1972, pp. 448-449)

Em 1937, Skinner propõe o comportamento operante ao identificar uma nova relação entre o organismo e o ambiente - relação entre a resposta e os eventos subsequentes. O comportamento operante e adoção da tríplice contingência como unidade de análise do comportamento terão desdobramentos para a construção do sistema explicativo. Skinner, em publicações posteriores, identifica semelhanças entre relações entre o organismo e ambiente que constituem o comportamento operante e a seleção natural:

Vimos que em certo aspecto o reforçamento operante se assemelha à seleção natural da teoria da evolução. Assim como características genéticas que surgem como mutações são selecionadas ou descartadas pelas suas consequências, também novas formas de comportamento são selecionadas ou descartadas pelo reforçamento. (Skinner, 1953/1965, p. 430)

Skinner baseará no comportamento operante a construção de sua filosofia (Skinner, 1974) e de suas propostas para a ciência. Para Skinner “... seu 'conhecimento' [do homem] é comportamento com relação a si próprio e ao mundo, e pode ser estudado como tal" (1957/1992, p. 451). A ciência do comportamento inclui assim o comportamento do cientista. Como afirma Skinner (1979), “... com a análise funcional do comportamento verbal baseada no estímulo discriminativo ao invés do estímulo eliciador - em outras palavras, com uma análise das contingências de reforçamento [do comportamento] verbal - encontrei o que acredito ser o significado de conhecer (p. 47)".

A análise do comportamento de conhecer - tanto de cientistas e filósofos - como comportamento operante verbal parece ter trazido dificuldades ainda maiores para a compreensão de suas propostas. Diferentemente de posições que defendem que a ciência deva ser funda- mentada em teorias da filosofia e da lógica, para Skinner cabe à ciência do comportamento o estudo dos processos de produção de conhecimento.

[...] a análise do comportamento produziu uma espécie de epistemologia empírica. O objeto da ciência do comportamento inclui o comportamento dos cientistas e de outros produtores de conhecimento. As técnicas disponibilizadas por tal ciência dão a uma teoria empírica do conhecimento certas vantagens sobre teorias derivadas da filosofia e lógica. (Skinner, 1963/1969, p. 228)

Skinner expõe, em 1981 no artigo "Selecion by consequences", uma nova noção de determinação do comportamento que denomina modelo de causalidade de seleção por consequência. Destaca três espécies de seleção pelas consequências - das espécies, do condicionamento operante e da cultura - que operam sobre variações que ocorrem, respectivamente, na espécie, no comportamento operante e nas práticas culturais.

o comportamento humano é o produto conjunto de (1) contingências de sobrevivência responsáveis pela seleção natural das espécies e (2) em contingências de reforçamento responsáveis pelos repertórios adquiridos por seus membros, incluindo (3) as contingências especiais mantidas por um ambiente social evoluído." (Skinner, 1981/1987, p.55)

Apesar de apresentar a seleção por consequências como um modelo de causalidade claramente em 1981, as diversas dimensões de determinações do comportamento humano já vinham sendo indicadas em publicações anteriores (Skinner, 1947/1972, 1953/1965, 1972, 1974). Em 1947, por exemplo, ao postular que o comportamento é submetido a leis, Skinner indica como parte da determinação do comportamento humano: 1. a constituição genética, produto da seleção natural; 2. a história pessoal, ou seja, a história de contingências de reforçamento, que produz o indivíduo e 3. o ambiente social, relacionado à terceira espécie de seleção - a envolvida nas práticas culturais. Nessa seleção, ressalta uma marca desse modelo causal - dar ao homem a possibilidade de controle, de ação na construção das condições que o determinam, uma vez que o homem pode agir sobre o ambiente social.

A constituição genética do indivíduo e sua história pessoal passada desempenham papel nessa [do comportamento humano] determinação. Além disso, o controle está no ambiente e as mais importantes forças estão no ambiente social que é um produto humano. O comportamento humano está portanto grandemente sob o controle humano. (Skinner, 1947/1972, p. 229)

Ao comparar a noção de determinação de 1931 com a expressa no modelo de seleção por consequências, observa-se que há uma mudança em relação aos pres- 
supostos sobre a existência do objeto de estudo, à relação que se estabelece entre sujeito e objeto no processo de produção do conhecimento e aos caminhos que permitiriam produzir tal conhecimento. A compreensão das propostas de Skinner para a ciência não pode ocorrer dissociada das transformações que ocorrem em sua visão de comportamento associadas à noção de seleção por consequências. Nesse artigo, busca-se identificar alguns desdobramentos do modelo causal de seleção por consequências para as propostas de Skinner para a ciência. A identificação de possíveis desdobramentos e mudanças que ocorrem em sua noção de ciência pode favorecer investigações que aprimorem a metodologia científica utilizada por analistas do comportamentos e ampliem a compreensão da ciência proposta por B. F. Skinner.

Foram inicialmente selecionados textos da primeira década da produção de Skinner para serem comparados com os da última década, momento em que o modelo de seleção pelas consequências foi explicitamente apresentado e seu sistema já estava desenvolvido com os fundamentos do behaviorismo radical. Da primeira década foram selecionados capítulos que apresentam discussões metodológicas: quatro $(30$ a 33$)$ do livro Cumulative Record (1972) e quatro (1, 2, 12, e 13) apresentados no livro The Behavior of Organisms (1938). Da última década todos os artigos publicados nos livros Upon Further Reflection e Recent Issues in the Behavior Analysis (1989) e seu último artigo (Skinner, 1990). Como na última década Skinner trabalha com conceitos propostos em artigos anteriores, às vezes de forma mais clara e completa, foram analisados artigos e capítulos de livros do período intermediário. Foram analisados o artigo "Are theories of learning necessary" (1950), sete capítulos (1, 2, 9, 10, 11, 18 e 19) do livro Verbal Behavior e os livros Contingencies of Reinforcement (1969), About Behaviorism (1974) e Reflections on Behavior and Society (1978). A partir da leitura dos textos selecionados foram identificados e transcritos trechos relativos a aspectos metodológicos: que discutiam suas concepções sobre objeto de estudo, o papel do pesquisador no processo de investigação, o conhecimento (critério de verdade, o papel do conhecimento produzido, a noção de causalidade) e os procedimentos que propunha para investigação (experimentação, análise, observação, elaboração de hipóteses, medidas etc.). Os trechos selecionados recebiam títulos que poderiam ser descritivos do conteúdo ou poderiam já envolver um grau de análise. Os trechos com títulos semelhantes foram agrupados em sequência cronológica e comparados, tentando identificar permanência ou alteração de critérios, definições etc. A organização e análise indicou que o sistema explicativo de Skinner apresenta alterações conceituais e metodológicas muitas delas relacionadas a mudanças na noção de causalidade.

\section{CONTINGÊNCIAS DE SELEÇÃO DO COMPORTA- MENTO DO CIENTISTA}

O conhecimento, segundo Skinner, é fruto de um comportamento complexo que aumenta a eficácia com que o homem opera sobre o mundo. A ciência favorece uma ação efetiva do homem frente ao ambiente pelo fato de, diferentemente de outros animais, o homem não ser só afetado pelas contingências de reforçamento. Ele é também capaz de analisá-las, ao fazê-lo pode descrever contingências de reforçamento predominantes no mundo físico e social. "A ciência é em grande parte uma análise direta dos sistemas de reforçamento encontrados na natureza, ela se preocupa com facilitar o comportamento que é reforçado por eles" (Skinner, 1966a/1969, p. 143). A ciência tem uma função fundamental nas práticas humanas por ser uma forma de ação sobre o ambiente voltada para consequências práticas. As leis científicas descrevem contingências de reforçamento predominantes no mundo físico e social.

Elas não são obedecidas pela natureza, mas por homens que lidam efetivamente com a natureza. ... A lei científica não obriga ninguém a se comportar de determinada forma, ela simplesmente descreve contingências sob as quais certos tipos de comportamentos terão certos tipos de consequências." (Skinner, 1966a/1969, p. 141-158)

É uma atividade que, por meio das descrições das contingências de reforçamento predominantes, tem possibilidade de criar condições para corrigir tanto falhas do processo evolutivo quanto das práticas sociais, ou seja, permite intervir no processo de seleção. As práticas culturais submetidas ao processo de seleção por consequências, segundo Skinner (1990), preparam o indivíduo para um mundo semelhante ao mundo em que a cultura evoluiu e produzem muitas culturas conflitantes. A ciência permite, pela análise das contingências presentes no mundo atual, prever possíveis consequências de tais práticas, ela pode produzir mutações, mais do que esperar que elas ocorram (Skinner,1987). Estas se colocam como variações entre outras práticas culturais para serem selecionadas por suas consequências. $\mathrm{O}$ conhecimento é avaliado em função de quanto permite uma ação efetiva sobre o ambiente, não em função de quanto é uma representação 
do mundo real. O conhecimento é avaliado pelas suas consequências.

A ciência do comportamento e sua filosofia têm caráter processual, mudarão constantemente na medida em que os processos comportamentais agora em estudo se alterarem. "Como uma filosofia crítica da ciência, ele [o behaviorismo] necessariamente mudará como a ciência do comportamento muda, e as questões correntes que definem o behaviorismo podem ser completamente resolvidas" (Skinner, 1963/1969, p. 267).

Como fruto de determinações ambientais, o comportamento do cientista se origina do reforçamento social de uma comunidade. "O cientista constrói um conjunto de respostas para uma situação dada por causa das contingências de reforço estabelecidas pela comunidade científica" (Skinner 1957/1992, p.127). O conhecimento do mundo, sendo um comportamento verbal, está submetido a possibilidades e limites de tais comportamentos. As descrições não são iguais às contingências que descrevem - não são tão completas, complexas e variadas como as contingências (Skinner, 1974; 1966a/1969). O comportamento do cientista está determinado pela sua história de reforçamento e pelo conjunto de contingências presentes no momento de sua ação.

Apesar destas limitações "a questão da ciência é analisar as contingências de reforçamento encontradas na natureza e formular regras ou leis que tornam desnecessário estar exposto a elas para se comportar apropriadamente" (1966a/1969, p. 166). Para tornar a ação efetiva a comunidade científica desenvolve formas de controle de tais limitações. A comunidade busca colocar o comportamento do cientista sob controle do que está sendo explicado, busca “... maximizar o controle exercido pelo estímulo e suprimir outras condições, tais como os efeitos incidentais provocados sobre o ouvinte que levam o falante a exagerar ou mentir" (1974, p. 259). A comunidade procura deixar o cientista sob controle do que acontece desenvolvendo técnicas que favoreçam isto. Segundo Skinner (1989)

Descobrimos as leis da natureza por meio da experiência - não, como os fenomenólogos o fariam, a partir da aparência das coisas na consciência, no sentido original da palavra experiência, mas a partir do que acontece. Os cientistas aperfeiçoam a experiência através da experimentação - fazendo coisas para ver o que acontece. (p. 43)

Apesar de afirmar que a pura objetividade nunca é alcançada (1957/1992, p. 83), Skinner considera que os métodos da comunidade científica buscam suprimir os interesses pessoais do pesquisador. Segundo Skinner,
(1974) "Quando os cientistas chegam aos mesmos fatos ou leis qualquer contribuição pessoal ou participação é reduzida ao mínimo." (p. 159)

\section{PRESSUPOSTOS SOBRE A EXISTÊNCIA DO OBJE- TO DE ESTUDO}

Pressupostos sobre a relação que se estabelece entre o sujeito que conhece e seu objeto de estudo podem ser identificados em suas proposições para a construção do conhecimento científico, ao longo de suas publicações e estão relacionados à adoção de pressupostos sobre a existência de tal objeto independentemente do sujeito. A explicitação de sua noção de determinação e explicação, em 1931, está acompanhada de afirmações de que é "desnecessária a suposição de que há um reflexo de flexão que existe independentemente de nossas observações e do qual nossas observações se aproximam. ... Um reflexo não tem significado aparte de sua definição em termos de tais operações experimentais [envolvidas na correlação observada entre estímulo e resposta]" (Skinner, 1931/1972, p. 452-453).

Entretanto, as afirmações futuras de Skinner relacionadas ao modelo de determinação de seleção por consequências evidenciam supostos bastante distintos em relação à existência do objeto de estudo.

O modelo causal de seleção por consequências, que ocorre com os organismos vivos, começa a operar desde que a primeira molécula viva capaz de se reproduzir passou a existir, portanto muito antes de qualquer forma humana capaz de conhecer ter evoluído. Tal modelo é pouco evidente à observação (Skinner, 1975b/1978), uma vez que o que pode ser observo é o produto do processo de seleção. O comportamento do homem é produto da história de sua espécie, de sua cultura e de história pessoal. Skinner (1972) atribui a descoberta tardia desse modelo explicativo ao fato dele ser menos "conspícuo" que a causalidade mecânica, o que justifica sua descoberta tardia pelo homem. O modelo de seleção por consequências explica o comportamento humano determinado por condições ambientais de dimensões espaciais e temporais diversas - da espécie, do indivíduo e da cultura -, das quais só podemos observar as relações de um determinado momento. Não podemos observar os processos de seleção. Como afirma Skinner (1966a/1969),

O contato sensorial com o mundo externo pode ser o começo do conhecimento, mas esse contato não é suficiente. Ele não é suficiente para a 'experiência consciente', uma vez que o estímulo é só parte da contingência de reforçamento sob a qual o organismo distingue entre as- 
pectos e propriedades do ambiente em que ele vive. Respostas devem ser dadas e reforçadas antes que qualquer coisa possa ser vista. (p. 156).

Skinner reafirma, em 1990, que esta noção de causalidade se refere a processos que ocorrem no mundo e não dependem do sujeito que os conhece: "tem-se dito também que a variação e seleção poderiam ocorrer no cérebro, mas embora o cérebro, como qualquer outra parte do corpo, experimente variação, as contingências de seleção estão no ambiente" (p. 1208).

Ao analisar o mundo e, desse modo, estabelecer fatos, leis e teorias que permitem a outras pessoas agirem efetivamente sem se expor a elas, o cientista teria possibilidade de produzir comportamentos novos. A preocupação, expressa em muitos momentos da sua obra, de que o cientista não estivesse norteado pelo teste de hipóteses, ou pela confirmação de teorias, parece estar relacionada aos fins que estabelece para o comportamento do cientista. É necessário que tal comportamento seja vinculado ao mundo. O que não significa que ele não defenda a construção de teorias.

As teorias devem ser produzidas, mas após os fatos - hipóteses e teorias vêm depois dos dados. As contingências vêm sempre em primeiro lugar. Segundo Skinner (1950), a teoria "não substituirá nossa pesquisa de variáveis relevantes e surgirá só depois que variáveis relevantes tiverem sido encontradas e estudadas" ( $p$. 216). Para Skinner, é patético um colecionador de fatos, que opera selecionando um fato contra outro. É preciso, segundo Skinner (1947/1972), ir além dos fatos, é preciso construir teorias. A teoria é importante para a compreensão do comportamento. A teoria não se opõe aos fatos, vai além dos fatos particulares, organiza-os e dá a eles utilidade. Ela aparece quando tentamos explicá-los (1950, p. 200). Sua defesa da teoria está também centrada na necessidade de substituir as teorias dominantes sobre o comportamento (mentalistas que explicam a partir do mundo interno, ou mecanicistas que explicam o comportamento, por exemplo, por meio de processos fisiológicos) por aquelas que explicam o comportamento pela ação ambiental. Para Skinner (1947/1972) é importante construir uma ciência do comportamento que "tome o lugar das teorias que agora prevalecem em nosso pensamento" (p. 311) e isto só seria possível com uma nova teoria do comportamento, pois "uma teoria nunca é derrotada por fatos, só por outra teoria" (1947/1972, p. 312).

\section{PROCEDIMENTOS QUE PERMITIRIAM PRODUZIR CONHECIMENTO}

Como produzir um conhecimento - construir leis e teorias - que descreva relações de contingências presentes no mundo, que será avaliado por sua efetividade, de um objeto que é processual e determinado por condições espaciais e temporais tão diversas que não se oferecem diretamente a observação? Que propostas podem ser identificadas nas análises de Skinner que indicam alternativas metodológicas compatíveis com a produção de conhecimento científico de um tal objeto?

Formas de investigar, propostas no início de sua obra, ganham novos significados em função de um objeto de estudo que, orientado pela noção de seleção por consequências, adquire novas dimensões. Algumas propostas iniciais sobre ciência resultam agora em uma união incomum: por um lado, um objeto que, submetido à causalidade da seleção por consequências, necessita de uma compreensão histórica e, por outro, uma proposta de previsão e controle que, para Skinner, decorrem de uma ciência experimental. Encontramos em sua obra referências a estas duas perspectivas.

A seleção por consequências como um modelo causal destaca o caráter processual e histórico do comportamento. Segundo Skinner, “... a análise do comportamento ... é necessariamente 'histórica' - quer dizer, ela está limitada a relações funcionais que revelam falhas temporais. Faz-se alguma coisa hoje que afeta o comportamento de um organismo amanhã" (1974, p. 236). E esta perspectiva histórica contida no conceito de operante e nos princípios decorrentes da seleção por consequências dará à noção de previsão e controle também um caráter histórico, o que torna limitado o conhecimento que se restrinja à observação do comportamento no momento em que ele ocorre. ".. as condições que determinam a forma de probabilidade de um operante estão na história da pessoa. Desde que elas não são conspicuamente representadas no cenário atual [current setting] elas são facilmente negligenciadas." (1974, p. 59)

É preciso compreender como Skinner, que originalmente tem uma visão de ciência vinculada a fatos observáveis, trabalha na produção de sua ciência baseado em princípios da seleção por consequências, nos quais a reconstrução histórica constitue procedimento fundamental.

\section{A experimentação}

Associada a esta discussão das dificuldades de ob- 
servação de um objeto de estudo constituído historicamente está a defesa da experimentação: a experimentação na situação controlada de laboratório mediante da manipulação de variáveis se mantém. Identifica-se também uma noção de experimentação ampliada, que extrapola os limites do laboratório para dimensões culturais a fim de transformar essas práticas. Experimentação parece ganhar um significado adicional no processo de variação e seleção constitutivo do modelo causal de seleção pelas consequências, experimentar pode significar também implantação de práticas alternativas às que vigoram em uma comunidade, ou de formas de controle diversificadas, que seriam testadas a partir de suas consequências, ou seja, seriam propostas como variação e selecionadas em função de suas consequências.

A ciência, entre as práticas culturais, pode intervir no processo de seleção produzindo variações a serem selecionadas. Em seu artigo 'What is wrong with daily life in wertern world', Skinner (1986) analisa as alternativas de conhecimento - tais estoicismo, epicurismo, iluminismo, racionalismo - propostas para resolver problemas gerados pela civilização, como "soluções que começaram como experiências pessoais que serviram como variações para serem testadas por seus efeitos sobre a sobrevivência dos grupos praticantes" (p. 573), mas não tiveram sucesso. Para ele a solução baseada em princípios científicos pode ser mais bem sucedida. A ciência do comportamento começa a conhecer as razões pelas quais as pessoas se comportam e elas podem ser mudadas. Para Skinner, a contribução da solução científica que poderia levar a uma mudança efetiva é a produção da variação:

Um novo conjunto de práticas não pode simplesmente ser imposto por um governo, religião ou sistema econômico; ele não seria um conjunto correto de práticas se isso fosse feito. Ele deveria desempenhar sua parte só como variações a serem testadas pelo seu valor de sobrevivência. As contingências de seleção estão além do nosso controle." (Skinner, 1986, pp. 574-575)

\section{A interpretação}

Além da apresentação de dimensões históricas do objeto de estudo e da experimentação, identifica-se a proposta de interpretação. Ao apresentar os objetivos da ciência, Holland e Skinner (1961) propõem como objetivos da ciência a previsão, o controle e a interpretação. Anos antes, Skinner (1953/1965) apresentou como objetivos a previsão e o controle.

Skinner defende a interpretação como parte da ciência exemplificando sua presença em outras ciências.
"Como ocorre em outras ciências, frequentemente carecemos das informações necessárias para previsão e controle e devemos satisfazermos com interpretação, mas nossas interpretações terão o apoio da previsão e controle que formam possíveis em outras condições" (Skinner 1974, p. 194).

A interpretação é retomada em outros momentos junto com a previsão e controle, inclusive ao analisar aspectos do conhecimento relacionados à teoria da evolução. Segundo Skinner, a teoria da evolução é uma interpretação de muitos fatos, sustentada por outras ciências, como a genética, a etologia, nas quais a previsão e controle são possíveis (1974, p. 248; 1987, p. 10 e p. 75).

Skinner parece ressaltar a importância da prática interpretativa adotada em sua produção na apresentação de duas importantes obras. Verbal Behavior é apresentado como um "exercício de interpretação mais que uma extrapolação quantitativa de resultados experimentais rigorosos" (Skinner, 1957/1990, p. 11). Em About Behaviorism adverte o leitor: "Grande parte da argumentação do livro vai além dos fatos estabelecidos. Estou mais preocupado com interpretação do que com previsão e controle" (Skinner, 1974, p. 21).Segundo Skinner (1984/1987), ao se explicar as origens do comportamento na história da espécie, opera-se, como na seleção natural, por especulações (1984/1987, p. 67), uma vez que não podemos observar o processo de seleção que produziu características genéticas. "As contingências responsáveis por um comportamento não aprendido atuaram muito tempo atrás. A seleção natural de uma determinada forma de comportamento, não importa quão plausivelmente argumentada, é uma inferência" (Skinner, 1966b/1969, p. 181).

Defende também a interpretação como procedimento utilizado pelo cientista quando não dispõe de dados que lhe permita previsão e controle, quando as condições não podem ser descritas com precisão e a história está fora do alcance. "Onde a previsão e controle não são ainda possíveis, nós devemos nos voltar à interpretação" (1987, p. 9). Isto não ocorre só no nível filogenético, mas também a nível ontogenético. Apesar das contingências ontogenéticas serem relativamente mais claras, estão também, em grande medida, fora do alcance da descrição, uma vez que elas pertencem a nossa história pessoal. Segundo Skinner (1974):

Quando o comportamento humano é observado sob condições que não podem ser exatamente descritas e onde as histórias estão fora do alcance, muito pouca previsão ou controle é possível, mas uma abordagem behaviorista é 
ainda mais útil que uma mentalista na interpretação do que uma pessoa está fazendo ou porque ela se comporta como o faz sob tais circunstancias. (1974, p. 230-231)

Além disso, diferentemente dos animais, nós humanos não estamos apenas expostos a contingências, nós podemos descrevê-las e tal descrição é produto da história do indivíduo.

Há outra razão por que a maior parte das explicações científicas do comportamento humano permanecem matéria de interpretação. A espécie se distingue pelo fato de que seus membros se engajam no comportamento verbal. Eles não só respondem a contingências de reforçamento como os ratos e os pombos fazem; eles falam sobre elas. Eles formulam regras e dão conselhos uns aos outros e a eles mesmos. .... Em qualquer ambiente, portanto, quer da vida diária ou do laboratório, o comportamento humano deve ser tratado como um produto articulado de contingências predominantes de reforçamento e do que uma pessoa diz sobre elas. Isto não significa que o comportamento não esteja submetido à lei, porque se nós conhecêssemos todos os fatos nós seríamos capazes de explicá-los, mas a maior parte do que as pessoas falam a si mesmas sobre o mundo no qual elas vivem é um produto da história pessoal e está fora do alcance. Por um longo tempo o comportamento humano provavelmente permanecerá assunto de interpretação mais do que predição e controle. (Skinner, 1987, p. 10)

$\mathrm{Na}$ impossibilidade de análise precisa, Skinner propõe que a especulação permita a elaboração de métodos que levem ao aumento do controle. Apenas a observação parece não ser suficiente para gestar novas alternativas mesmo que ela seja orientada por um sistema que guie a coleta de dados, como Skinner propunha, em 1938. "Especulação", "interpretação", "idealização" ganham espaço na produção de novas alternativas, quer metodológicas quer relativas à transformação das contingências que alteram o comportamento.

Cada campo científico tem uma fronteira além da qual a discussão não pode ser tão precisa quanto se desejaria. Um escritor disse recentemente que 'a mera especulação que não pode ser posta em teste experimental não faz parte da ciência', mas se isto fosse verdade grande parte da astronomia, ou da física atômica não seria ciência. A especulação é necessária de fato para a ideação de métodos que irão trazer o objeto sob maior controle. (Skinner, 1974, p. 21)

O procedimento interpretativo, que ocorre na ciência da evolução fundada em pesquisas genéticas experimentais, é apontado por Skinner como modelar para a ciência do comportamento. Como as pesquisas genéticas permitem interpretar fatos da evolução, Skinner propõe que a ciência do comportamento a partir dos resultados do laboratório interprete o comportamento fora dele, onde a previsão exata ainda não é possível (1974, p. $251 ; 1986 / 1987$, p. 75 )
Podemos dizer que a observação direta do comportamento defendida em 1931 é colocada em novas bases ao abordar o caráter histórico dos determinantes do comportamento e a necessidade de interpretar para conhecê-los. Skinner, em 1931 afirma “... o comportamento [a resposta] e o estímulo têm uma importância particular, porque só eles são diretamente observáveis nos organismo intactos ... A descrição do comportamento [aqui igual à explicação] está preocupada com relações destes dois termos... (1931/1972, p. 448-449)

Em 1987, discutindo consciência e autogoverno e as contingências do ambiente verbal neles implicados, indica a interpretação como prática científica a ser realizada para explicar o que não pode ser controlado experimentalmente:

Boa parte disso, no momento, é apenas ainda uma interpretação, mas esta é prática científica comum. Astrônomos interpretam as ondas e as partículas que atingem a Terra, provenientes do espaço exterior pelo uso do que foi aprendido em condições controladas de laboratório - por exemplo, na física de alta energia. De modo semelhante, nós usamos o que foi aprendido na análise experimental para explicar o que não pode, no mínimo no momento, ser trazido sob controle experimental, tal como eventos encobertos ou comportamento observado casualmente na vida diária. $(1987 / 1989$, p. 63$)$

\section{A união de procedimentos}

A interpretação parece ganhar espaço nas formulações da fase final da obra de Skinner e se associar à experimentação. A análise experimental, em que a previsão e controle são possíveis, é proposta como "a genética das culturas humanas", porque a partir dela seriam possíveis interpretações para a ação humana. Segundo Skinner (1987), “A teoria da evolução é uma interpretação, mas está fortemente sustentada por uma ciência em que a predição e o controle são possíveis - a ciência genética. A análise experimental do comportamento é a 'genética' das culturas humanas" (p. 10).

A interpretação é proposta, entretanto, sem que se abdique do suposto de que o conhecimento deve partir do que ocorre no próprio mundo. Neste sentido, é preciso analisar como a interpretação se conjuga com a observação e a manipulação neste sistema com dimensões históricas.

Garantir formas efetivas de ação sobre o mundo, para Skinner, depende fundamentalmente da possibilidade de prever e controlar, que exigem uma ciência experimental. Apesar de indicar a insuficiência da observação para produção de conhecimento, Skinner valoriza a observação, a busca de indícios acessíveis 
que permitam a análise de processos comportamentais e a experimentação. Isso parece ficar evidente nas passagens em que Skinner destaca as vantagens, em termos da produção de conhecimento, da ciência do comportamento (relativa ao comportamento operante) frente às outras ciências que ele considera de variação e seleção: a etologia (relativa à seleção natural do comportamento da espécie) e parte da antropologia (relativa à evolução dos ambientes sociais). Dentre os três níveis de variação e seleção, só "o condicionamento operante ocorre com rapidez suficiente para ser observado do começo ao fim. Por esta mesma razão [a análise do comportamento] é a única das três ciências [de variação e seleção] que pode ser usada para propósitos práticos da vida diária" (1990, p. 1206-1208)"; só ele ocorre na velocidade que pode ser observada de momento a momento - "o condicionamento operante é a seleção em processo" (Skinner 1981/1987, p. 55).

Skinner defende o caráter experimental da ciência do comportamento, que dá a ela a possibilidade de investigar contingências de reforçamento, controlar variáveis, modelar comportamento, avaliar práticas culturais e descobrir princípios que permitirão interpretar processos da vida prática. "Talvez a maior contribuição que uma ciência do comportamento pode dar para a avaliação de práticas culturais é insistir na experimentação" (Skinner, 1953/1965, p. 436).

$\mathrm{O}$ estudo do comportamento operante nos fornece a possibilidade, própria às ciências experimentais, de controle e previsão, que são propostas em termos probabilísticos. É probabilístico não só pelo fato de o conhecimento experimental fornecer sempre um conhecimento em termos de probabilidade, como também pelo fato de que o controle nunca é e não pode ser total. As formas de controle são práticas propostas que somadas a outras práticas presentes no ambiente se submeterão à seleção. "Ambos, a predição e o controle, são inerentes ao condicionamento operante, mas a noção é sempre probabilística e podemos lidar com a probabilidade quando não está ocorrendo a ação" (Skinner, 1974, p. 249). Mas como afirma Skinner (1986) a "probabilidade é uma "medida difícil para definir e medir" (p. 572). Skinner mantém a medida da probabilidade através da taxa de resposta e defende a possibilidade de manipulação do comportamento em situação de laboratório como medida da força de um comportamento operante. Para Skinner, os ambientes em que os animais vivem são muito diferentes daqueles que foram selecionados e a investigação de laboratório, apesar de arbitrária, é natural como qualquer em outro ambiente. Mas
Skinner (1966b/1969) faz uma ressalva: “... os reforços dispostos na análise experimental devem provar ter correspondência com a vida real, para que os resultados da análise sejam significativos e úteis"(p. 181).

As vantagens que Skinner (1981/1987) atribui ao operante na construção do conhecimento parecem estar na possibilidade de este processo envolver observação e manipulação de fatos obtidos sistematicamente em oposição à história que elabora seu conhecimento por reconstrução - “... os historiadores procedem por reconstrução do que aconteceu, mais do que pelo exame de fatos registrados" (p. 51). A mera reconstrução de fatos, procedimento que identifica como característico do historiador, parece não ser suficiente. "Só o comportamento operante pode ser observado de momento a momento. Biólogos e antropólogos estudam processos através dos quais variações surgem e são selecionadas, mas eles meramente reconstroem a evolução de uma espécie ou uma cultura" (Skinner, 1981/1987, p. 55).

Skinner trabalha com reconstrução em vários textos que discute a origem do comportamento. Em "The evolution of verbal behavior", por exemplo, ele está preocupado com a evolução do ambiente verbal como origem do comportamento de um falante e faz o que poderia ser chamado de reconstrução desta origem. Afirma que: "A plausibilidade da reconstrução depende em parte do tamanho das variações que é possível admitir que tenha ocorrido... A evolução do comportamento é também mais plausível se consideramos como produto de uma série de pequenas variações e seleções" (1986/1987, p. 76).

Em síntese, a análise do conhecer como comportamento operante verbal e a nova noção de determinação do modelo de seleção pelas consequências trouxeram alterações para a proposta de Skinner para o conhecimento. Ele descreve contingências de seleção dispostas pela comunidade científica para permitir que o comportamento do pesquisador fique sobre controle do evento a ser explicado. O pressuposto de que o objeto de estudo, que resulta de três espécies de determinação, existe independentemente do pesquisador substitui o pressuposto inicial de que esta é questão uma sem significado para a ciência, apresenta em 1931 ao propor o conceito de reflexo para o estudo do comportamento. Nesse novo modelo de determinação, a identificação das dimensões históricas do comportamento está acompanhada da análise de que a observação direta do comportamento é insuficiente para produção do conhecimento científico e de que a interpretação, pro- 
cedimento já utilizado por outras ciências, possibilita compreender o comportamento que resulta diferentes determinantes históricos. A experimentação, além da realizada no laboratório, se estende para a produção de práticas culturais alternativas e a intervenção nas práticas culturais, baseada no conhecimento científico, é descrita como produção de variações que serão selecionadas por suas consequências. As transformações identificadas, relacionadas ao modelo de seleção pelas consequências, parecem indicar que Skinner considera que a produção de um conhecimento efetivo envolveria conjugar a interpretação, a experimentação e observação.

Podemos supor, como Skinner afirma explicitamente, que o conhecimento obtido no laboratório será usado para interpretar a vida diária (1974, p. 251), os eventos internos e os próprios processos genéticos (1986/1987, p. 76). E, na análise da vida far-se-iam especulações e interpretações como reconstruções que permitiriam compreender a origem de determinadas práticas, condição necessária para a transformação.

É possível identificar estas duas alternativas - histórica e experimental - na obra de Skinner. Não há explicitação clara de procedimentos metodológicos para se trabalhar com as dimensões históricas envolvidas na seleção por consequências. Foram apenas identificadas algumas vantagens indicadas por Skinner que se tem no laboratório ao se estudar o condicionamento operante do começo ao fim, de momento a momento. Os limites dos estudos de laboratório, realizados pela análise experimental, chegam a ser apontados, mas sem que ameacem as contribuições que tais estudos proporcionam. Segundo Skinner (1974):

As contingências atualmente em investigação, embora extremamente complexas, são muito menos complexas que as da vida diária, ainda é quase impossível descobrir que está acontecendo ... A análise de laboratório torna possível identificar variáveis relevantes e desconsiderar outras que, possivelmente mais fascinantes, têm, entretanto, pouca ou nenhuma relação com o comportamento em observação. Muitos dos avanços tecnológicos derivam do estudo do comportamento operante e foram beneficiados por esta espécie de interpretação. (pp. 252-253)

Apesar de sua ênfase na análise experimental do comportamento, muito de sua obra (Skinner, 1957/1992, 1974), talvez a maior parte dela, se refere à análise do comportamento em que - interpretando a partir dos resultados do laboratório - especula, infere e reconstrói as determinações relativas à espécie, ao comportamento operante e às práticas culturais.

A análise de aspectos da proposta de ciência nas ba- ses do modelo de seleção por consequências indica a necessidade de que os analistas do comportamento se dediquem ao estudo de metodologias de investigação da ciência que ampliem as análises dos comportamentos envolvidos na produção de uma ciência efetiva. Uma indicação que só reforça a conclusão de Skinner (1957/1992) de que "os processos verbais do pensamento lógico e científico merecem e exigem uma análise mais precisa do que a que eles têm recebido até agora" (p. 431).

\section{REFERÊNCIAS}

Bjork, D. W. (1996). B. F. Skinner and the American tradition: The scientist as social inventor. In L. D. Smith \& W. R. Woodward (eds), B. F. Skinner and behaviorsm in american culture (pp.35-55). Cranburry, NY: Lehigh University

Holland, J. G., \& Skinner, B. F. (1961). The analysis of behavior: A program for self-instruction. New York, NY: McGraw Hill.

Skinner, B. F. (1938). The behavior of organisms: An experimental analysis. New York, NY: Appleton-CenturyCrofts.

Skinner, B. F. (1950). Are theories of learning necessary? The Psychological Review, 57, 193-216. http://dx.doi.org/10.1037/h0054367

Skinner, B.F. (1965). Science and human behavior. New York: The Free Press. (Trabalho original publicado em 1953)

Skinner, B. F. (1969). Behaviorism at fifty. In Contingencies of reinforcement: A theoretical analysis (pp. 221-268). New York, NY: Appleton-Century-Crofts. (Trabalho original publicado em 1963)

Skinner, B. F. (1969). An operant analysis of problem solving. In Contingencies of reinforcement: A theoretical analysis (pp. 133-171). New York, NY: Appleton-Century-Crofts. (Trabalho original publicado em 1966a)

Skinner, B. F. (1969). The phylogeny and ontogeny of behavior. In Contingencies of reinforcement: $A$ theoretical analysis (pp. 172-220). New York, NY: Appleton-Century-Crofts. (Trabalho original publicado em 1966b)

Skinner, B.F. (1972). The concept of reflex in the description of behavior. In Cumulative record (pp. 429-457). New York, NY: Appleton-Century-Crofts. (Trabalho original publicado em 1931)

Skinner, B.F. (1972). Two types of conditioned reflex: a reply to Konorsky and Miller. In Cumulative record (pp. 489497). New York, NY: Appleton-Century-Crofts. (Trabalho original publicado em 1937)

Skinner, B. F. (1972). Current trends in experimental psychology. In Cumulative record (pp. 295-313). New York, NY: Appleton-Century-Crofts. (Trabalho original publicado em 1947)

Skinner, B. F. (1972). A lecture on "having" a poem. In $\mathrm{Cu}$ mulative record (pp. 345-355). New York, NY: AppletonCentury-Crofts. 
Skinner, B. F. (1973). Answers for my critics. In H. Wheeler (Ed.), Beyond the punitive society (Operant conditioning. Social and politic aspects) ( pp. 256-266). San Francisco: W. H. Freeman.

Skinner, B. F. (1974). About behaviorism. New York: Vintage.

Skinner, B. F. (1978). The shaping of phylogenic behavior. In Reflections on behaviorism and society (pp. 163-170). Englewood Cliffs, NJ: Prentice-Hall. (Trabalho original publicado em 1975a)

Skinner, B. F. (1978). Why I am not a cognitive psychologist. In Reflections on behaviorism and society (pp. 97-112). Englewood Cliffs, NJ: Prentice-Hall. (Trabalho original publicado em 1975b)

Skinner, B. F. (1979). B. F. S. A. interviews B. F. Skinner. Behaviorists for Social Action Journal, 2, 47-52.

Skinner, B. F. (1986). What is wrong with daily life in the western world? American Psychologist, 41, 568-574. http://dx.doi.org/10.1037/0003-066X.41.5.568

Skinner, B. F. (1987). Selection by consequences. In Upon further reflection (pp. 51-64). Englewood Cliffs, NJ: PrenticeHall. (Trabalho original publicado em 1981)

Skinner, B. F. (1987). The evolution of behavior. In Upon further reflection (pp. 65-74). Englewood Cliffs, NJ: Prentice-Hall. (Trabalho original publicado em 1984)
Skinner, B.F. (1987). The evolution of verbal behavior. In Upon further reflection (pp. 75-92). Englewood Cliffs, NJ: Prentice-Hall. (Trabalho original publicado em 1986)

Skinner, B.F. (1987). Why we are not acting to save the world. In B.F. Upon further reflection (pp. 1-14). Englewood Cliffs: Prentice-Hall.

Skinner, B. F. (1989). Whatever happened to psychology as a science of behavior? In Recent issues in the analysis of behavior (pp. 59-72). Columbus, OH: Merrill. (Trabalho original publicado em 1987)

Skinner, B. F. (1989). The listener. In Recent issues in the analysis of behavior (pp. 35-48). Columbus, OH: Merrill.

Skinner, B. F. (1990). Can psychology be a science of mind? American Psychologist, 45, 1206-1210. http://dx.doi.org/10.1037/0003-066X.45.11.1206.

Skinner, B.F. (1992). Verbal behavior. Acton, MA: Copley Publishing Group. (Trabalho original publicado em 1957)

Recebido em: 27/06/2016 Primeira decisão editorial em: 07/10/2016 Aceito em: 10/11/2016

Nota:

1 Este trabalho se baseia em partes de Micheletto, N. (1995) Uma questão de consequências: elaboração da proposta metodológica de B. F. Skinner. Tese de Doutorado, defendida na Pontifícia Universidade Católica de São Paulo. 